\title{
RAÍZES DA ESCOLÁSTICA MEDIEVAL NA CONTROVÉRSIA DE VALLADOLID SOBRE A LEGITIMIDADE DA CONQUISTA DE ÍNDIAS
}

\author{
ROOTS OF MEDIEVAL SCHOLASTICS IN THE VALLADOLID \\ CONTROVERSY ABOUT THE LEGITIMACY OF THE CONQUEST OF \\ THE INDIES
}

\author{
RAÍCES EN LA ESCOLÁSTICA MEDIEVAL EN LA CONTROVERSIA \\ DE VALLADOLID SOBRE LA LEGITIMIDAD DE LA CONQUISTA DE \\ INDIAS
}

Juan Pablo Martín RODRIGUES*

\begin{abstract}
Resumo: A Junta de Valladolid (1550-51) foi o fórum consultivo do Imperador de natureza jurídica, filosófica e teológica da Controvérsia sobre a legitimidade da Conquista de Índias. Os contendentes Frei Bartolomeu de Las Casas, dominicano, como representante de uma boa parte da Igreja, e o Doutor Sepúlveda, como humanista e defensor dos encomenderos - debateram direitos indígenas, civilização e barbárie, ou o direito à guerra justa contra os indígenas. Pouco se tem analisado o pensamento medieval nesta polêmica, que Zabala, Dussel ou Mignolo consideram marco inicial da primeira modernidade. O corpus analisado é o Democrates Alter, de Sepúlveda, e a Brevísisma Relação da Destruição das Índias, de Las Casas. Partir-se-á da ideia de Las Casas, como idealizador, teórico e defensor dos direitos indígenas, e Sepúlveda, como alma mater do pensamento imperial moderno (RODRIGUES, 2006, 2010), e da Revolução da Duodécima Réplica, de Las Casas, no referente à evolução final e surpreendente do pensamento lascasiano sobre a Conquista de Índias (VIDAL ABRIL, 1984). Concluise que há uma considerável influência do pensamento medieval e especialmente tomista em ambos contendentes do debate sobre a Conquista de América.
\end{abstract}

Palavras-chave: Pensamento Medieval. Controvérsia de Valladolid. Direitos Indígenas.

Resumen: La Junta de Valladolid (1550-51) fue foro consultivo del emperador, de naturaleza jurídica, filosófica y teológica de la Controversia sobre la legitimidad de la Conquista de Indias. Los contendientes son Fray Bartolomé de Las Casas, dominico, como representante de una buena parte de la Iglesia y el Doctor Sepúlveda, como humanista y defensor de los encomenderos, debatieron derechos indígenas, civilización y barbarie, o el derecho a la guerra justa contra los indígenas. Poco se ha analizado el pensamiento medieval en esta polémica sobre la que Zabala, Dussel o Mignolo consideran marco de la primera modernidad. El corpus analizado es el Democrates Alter de Sepúlveda y la Brevísima Relación de Destrucción de Indias, de Las Casas, como idealizador, teórico y defensor de los derechos indígenas y Sepúlveda como alma mater del pensamiento imperial moderno (RODRIGUES, 2006, 2010) y de la Revolución de la Duodécima Réplica de Las Casas en lo referente a la evolución final y sorprendente del pensamiento lascasiano sobre la Conquista de Indias (VIDAL ABRIL, 1984). Se concluye que hay una considerable influencia del pensamiento medieval y tomista en especial en ambos contendientes del debate sobre a Conquista de América.

Palabras Clave: Pensamiento Medieval. Controversia de Valladolid. Derechos Indígenas.

\footnotetext{
* Doutorado em Teoria Literária pelo Programa de Pós-Graduação em Letras da Universidade Federal de Pernambuco (PPGL/UFPE); Professor Associado I da UFPE, na área de Ensino de Língua e Literaturas em língua espanhola. E-mail: jpabloburgos@ @mail.com. ORCID id: https://orcid.org/0000-0002-2724-1205.
} 


\begin{abstract}
The Valladolid Debate (1550-51) was the emperor's consultative forum, of a legal, philosophical and theological nature, for the controversy over the legitimacy of the Conquest of the Indies. The contenders - the Dominican Fray Bartolomé de Las Casas, as representative of a good part of the Church and Doctor Sepúlveda, as humanist and defender of the encomenderos - debated about indigenous rights, civilization and barbarism, or the right to a just war against the indigenous. Little has been analyzed of medieval thought in this controversy, which Zabala, Dussel and Mignolo consider the framework of early modernity. The corpus analyzed is Sepulveda's Democrates Alter and Las Casas' Brief History of the Destruction of the Indies, as an idealizer, theoretician and defender of indigenous rights and Sepulveda as the alma mater of modern imperial thought (RODRIGUES, 2006, 2010) and of the Revolution of the Twelfth Replica of Las Casas with regard to the final and surprising evolution of Las Casas' thought on the Conquest of the Indies (VIDAL APRIL, 1984). It is concluded that there is a considerable influence of medieval and Thomistic thought, especially in both contenders of the debate on the Conquest of America.
\end{abstract}

Keywords: Medieval thought. Valladolid Debate. Indigenous Rights.

Dios concedió a los romanos un imperio muy dilatado y glorioso para impedir los males graves que cundían en los muchos pueblos que en busca de la gloria tenían ansias de riqueza y otros vicios. (Santo Tomás cita Santo Agostinho em SEPÚLVEDA, Democrates Alter, 1892).

Devido aos problemas de consciência gerados pela Conquista de América, o Imperador do Sacro Império Romano-Germânico, Carlos V, decidiu convocar a Junta de Valladolid no ano de 1550 para decidir sobre a legitimidade da Guerra contra os índios. Tratava-se de uma Junta deliberativa, mas com grande força vinculante moral e política, considerando que nela estavam os principais membros do Conselho Real e de Índias. Para tal, foram convocados um conjunto de notáveis juristas e teólogos, entre eles Juan Ginés de Sepúlveda e Las Casas. O primeiro - Cronista Real de Índias, confessor pessoal do Imperador Carlos e preceptor do príncipe Felipe, doutor em Letras e Teologia, discípulo de Pomponazzi -, defendendo a legitimidade imperial na guerra contra os bárbaros, será um dos primeiros humanistas da Espanha, embora apresente importantes traços de filosofia medieval na sua obra e pensamento, integrando os primeiros Padres da Igreja, Santo Tomás e Santo Agostinho (SEPÚLVEDA, 1997; RODRIGUES, 2006).

Frente a ele, Las Casas - primeiro sacerdote ordenado na América, incialmente colonizador e encomendero, convertido à causa indígena e nomeado pelo regente Cisneros "Defensor dos Índios", Bispo de Chiapas e representante da Ordem dos Predicadores - retoma os argumentos de outro dominicano, o professor da Universidade de Paris, Frei Francisco de Vitória, servindo-se do Neo-escolasticismo mais tomista para, paradoxalmente, criar um pensamento que pretende dar conta das novas realidades como incansável defensor e advogado 
dos indígenas e da Igreja Católica no Novo Mundo, como último garante de tais direitos. Não houve veredicto final nesta polêmica já clássica (ANABIARTE, 1992).

Há alguns aspectos da Colonização de América e a subsequente reflexão jurídica e filosófica que não têm sido suficientemente divulgados, como o das profundas raízes medievais da Conquista do Novo Mundo. Não será difícil encontrar resíduos ou práticas discursivas medievais mais do que evidentes na narrativa de Conquista, notadamente nas Crónicas de Índias, elaboradas por um Corpo de Cronistas Reais, que teve origem nas práticas discursivas escritas das Cortes medievais nos diversos reinos da Península. A importância dos discursos milenaristas do imaginário medieval - tanto como motor utópico mobilizador de recursos e acicate de aventureiros, predominantemente privados, em busca de benefícios pessoais e societários, de gloria mundi, mas também de gloria aeterna, quanto como informador dos processos perceptivos e intelectivos das novas realidades, vistas, escritas e anotadas em cartas de relação, ensaios, crônicas, confissões, relatos de viagens ou mapas que estão informados predominantemente desse imaginário mítico pré-renascentista, dado que eram locais totalmente desconhecidos para os europeus da época são bem explicados por Fernando Ainsa (1992). Sobre os aspectos medievais da Guerra Justa, pode-se consultar diretamente o Democrates Alter, de Sepúlveda (1792), ou, conforme Jorge Luis Gutiérrez (2007:79), no seu livro Aristóteles em Valladolid. O que se pretende neste breve trabalho é destacar a influência medieval na filosofia que fundamenta a Controvérsia de Valladolid e, notadamente, o papel do corpo dentro desta polêmica, um aspecto, talvez, pouco tratado até agora quando se trata da polêmica Las CasasSepúlveda. Esta Controvérsia tem sido quase sempre analisada através do ponto de vista filosófico, político ou teológico por especialistas como Hanke (1988); Lucena, González, Vidal Abril, Ramos (1983); Pereña (1984); Pérez Fernández (1995); Dumont (1997); Rodrigues (2006, 2010); Someda (2012). Em tais estudos, o corpo está sempre presente como pano de fundo e, certamente, como objeto direto das ações de Conquista, mas raramente como objeto principal de reflexão.

A importância deste debate para o leitor contemporâneo será precisamente o confronto entre livre arbítrio coletivo dos povos originários e a civilização a eles imposta. O poder sobre a própria integridade corpórea dos indivíduos como condição sine qua non da autonomia local da coletividade seria resistência frente à primeira globalização, que exigiria como tributo a submissão dos corpos a uma disciplina de produção ao serviço do sistema-mundo implantado a partir do século XVI (DUSSEL, 1998). Tal imposição implica uma alienação teológica - na substituição, pelo menos, da externalidade oficial dos Deuses pelo Deus Judaico-cristão - que 
exige também a submissão individual da livre vontade, assim como a subsequente perda de autonomia política que o Império exige.

Carlos Fuentes (2011, p. 12) formula um princípio que bem poderia ser fundamento inicial deste trabalho: "La invención de América es la invención de Utopía: Europa desea una utopía, la nombra, la encuentra para al cabo, destruirla”. Afinal, serão duas utopias as que se confrontam em Valladolid, ambas de raiz medieval: a de Sepúlveda frente à de Las Casas; a utopia imperial salvacionista e civilizadora frente à utopia universalista dos direitos dos seres humanos e dos povos que os acolhem e informam. Para Sepúlveda (1997, p. 92), é licito compelir aos índios a participar do banquete, que simboliza a salvação de participar da Igreja, como explica a parábola bíblica do convite: "Y dijo el señor al siervo: sal a los caminos y cercados y obliga a todos a entrar hasta que se llene mi casa”. O sustentáculo em Santo Agostinho é explícito neste caso, quando se afirma: Aunque yo digo que han de ser dominados los indios no sólo para que
escuchen a los predicadores, sino también para que a la doctrina y los consejos
se unan además las amenazas y se infunda el terror, lo que confirma San
Agustín en su respuesta epistolar al donatista Vicencio: "Si se les aterrase"
dice, "y no se les instruyese, parecería como un dominio inicuo; pero a la vez,
si se les instruyese y no se les aterrase, se endurecerían con la antigüedad de
la costumbre y demostrarían menos interés en el camino de la salvación".
(SEPÚLVEDA, 1997, p. 94).

A ideia de incorporação dos indígenas que persegue Juan Ginés de Sepúlveda baseia-se em princípios medievais mais ambiciosos - na afirmação do augustinismo político (RODRIGUES, 2006) -, fundamentado na perseguição da unidade espiritual - significado último de "católico" - da Igreja sob a guia de um Papa, e o necessário Império político para o sustentar, na teoria das duas espadas, que Carlos V tenta reviver quando se coroa Imperador do Sacro Império Romano-Germânico pelo Papa diante dos príncipes alemães. De fato, o emblema imperial de Carlos está inserido dentro do peito de uma águia com duas cabeças (RODRIGUES, 2006).

Esse programa imperial com profundas raízes no salvacionismo medieval é enunciado assim por Sepúlveda na Exhortatio Ad Carolum V (1963, 24):

En lo sucesivo "no lucharás por la conquista de un reino pobre", como dijo cierto autor, sino que se te propone como premio, si sales vencedor de esta santísima y sacratísima guerra, el imperio sobre muchos reinos y sobre la región más grande y rica del mundo, pues con la máxima expectación te esperan con ansia Grecia, Tesalia, Macedonia y Tracia (...) subyugar el Ponto, la Frigia, Bitinia, Capadocia, Licia, Cilicia y las demás provincias de Asia 
Menor y con Arabia, toda Siria, de la que es parte Judea y la sagrada ciudad de Jerusalén. (SEPÚLVEDA, 1963, p. 24).

A utopia medieval de recuperação dos Santos Lugares, e as conseguintes aventuras dos cruzados, confere um lugar eminentemente secundário para a "quarta parte do Orbe", precursor deste lugar subalterno da América na parte cálida do planeta:

Y después de haberte apoderado de estas provincias, ¿qué reino, qué nación podría oponerse a tus fuerzas, puesto que puedes ampliar este mundo de tres partes con aquel que, según dicen, habitan los antípodas, añadido hace poco al dominio español y a la Religión cristiana bajo los auspicios de tu abuelo Fernando y los tuyos, lo que puede facilitarte medios abundantes para mantener ampliamente tus fuerzas, aunque fueran más numerosas de lo que dijimos? (SEPÚLVEDA, 1963, p. 25).

Termina o opúsculo com uma afirmação piedosa, com fundas raízes no providencialismo medieval, embora plenamente renascentista no que tange à união de interesses sacros e profanos, na obtenção da Gloria Aeterna e da Gloria Mundi. Neste sentido, a enunciação destes princípios será a carta de apresentação de Juan Ginés de Sepúlveda perante o Cortejo de Carlos V quando visita a Corte Papal, da qual formava parte o cordoves, e, como humanista, redige a Exhortatio ad Carolum $V$, para que, feita a paz com os reinos cristãos, faça a guerra contra os turcos, publicada em Bolonha, em 1529, que termina enunciando esse programa providencial e piedoso, como segue:

Y una vez que te hayas apoderado de la riquísima región de Asia Menor y de los pueblos confines de Mesopotamia y Egipto, podrás adorar vencedor a Dios en la santa ciudad de Jerusalén, testigo ocular de nuestra redención y primero y principal sagrario de la Religión cristiana; le venerarás con suma piedad, con los debidos sacrificios por tan gran victoria, y al mismo tiempo con justas preces le pedirás que, ya que favoreció tus comienzos, Él mismo sea guía y autor de que, bajo tu imperio y dirección de la guerra, el resto del mundo se una al dominio de los cristianos y a su santísima Religión.

Sepúlveda utiliza vestes e fundamentos medievais a partir de autores reverenciados nessa época para elaborar uma base teórica que sustente todo o seu edifício conceitual no seu Democrates Alter. São Gregório (1997, 45,81, 92, 105, 108,122) Santo Isidoro (1997, 49,53,64,110,121), Pontífice Inocêncio (1997, 51, 61) Santo Tomás (1997, 63,75,81,103,106,124), Santo Ambrósio (1997,81,112), Gregório IX(1997, 89), São Bernardo (1997,99), São Cipriano (1997, 103), São Ambrósio (1997, 106), São Jerônimo (1997, 121). Dessa forma, utiliza esse arcabouço focado no seu auditório de juristas e teólogos neoescolásticos para revestir a ideia moderna de arrecadar recursos que permitam a expansão dos territórios do Príncipe, no que não diverge no enunciado por Colombo no Livro das 
Profecias. Neste, o genovês formula o ideário da perseguição das grandes utopias do medievo: a Conversão Universal e a recuperação dos Santos Lugares (implicitamente, do Santo Graal e das relíquias de Terra Santa), como locais exclusivos para o culto e peregrinação dos cristãos, cumprindo a Conquista de América um papel subalterno e instrumental para tal fím. Será a tal base utópica, fundamento desta Exhortatio, a que finalmente decide Carlos $\mathrm{V}$ a convidar Sepúlveda para ser Cronista imperial, confessor pessoal e preceptor do futuro Imperador Felipe II.

A segunda e oposta concepção utópica parte do outro contendente da Controvérsia de Valladolid, Bartolomé de Las Casas, o frade dominicano, polêmico e polemista bispo chiapateco. Entre os primeiros padres a chegar ao Novo Mundo, ele presenciou os primeiros contatos e escrevera, através dos testemunhos oculares e da própria experiência como colonizador inicial, a Brevíssima Relação de Destruição das Índias, sua obra mais traduzida e publicada em numerosas línguas. Antes disso, e da volumosa obra História das Índias, publicada postumamente, emitira, já em 1516, o Memorial de Remédios para las Índias, encaminhado ao regente Cisneros, no qual enuncia os princípios básicos de uma proposta utópica. Transcrevo parte do segundo remédio:

Segundo remedio: que porque el haberse muerto los indios, y morirse cada día, principalmente, ha estado y está em dallos y repartillos a singulares personas, que em a uno por sí para dellos se sirva y a esta causa todas las otras de su muerte acompañan y asimismo dela dependen; que vuestra señoría mande hacer una comunidad em cada villa y cuidad de los españoles, em que ningún vecino tenga indios conocidos ni señalados, sino que todos los repartimientos estén juntos, y los que hubieran de coger oro lo cojan juntos. Y apara ellos que haya mayordomos, los que fueren menester y otros ministros necesarios para la dicha comunidad, que abajo se nombrará, los cuales no tengan en ella ni en el provecho dela parte alguna, así en las labranzas que hicieren con los indios como en el oro que con ellos cogieren, salvo ciertos salarios y partido que se les dé en dinero a las funciones, cuando todos los gastos se pagaren, como más largo se dirá. Y de todos los conucos o labranzas que hicieren en cualquiera parte y lugar que fueren menester hacerse y de todo el oro que se cogiere, después de fundido em cada fundición, sacado el oro primerio el quinto de S.A. y para y pagados toso los gastos que en la dicha comunidad se hubieren hecho, así de salarios a los oficiales o ministros della, como de herramientas o otra cosa que se haya de pagar, sin da cada vecino o otra persona que las hicieren merecer. (LAS CASAS, 1958, p. 6).

Ditas propostas programáticas não se limitaram a um simples catálogo de remédios, mas informaram a ação efetiva e eficaz de Bartolomeu de Las Casas, não apenas no campo de polemista, cronista de Índias e propagandista da causa indígena, mas com realizações mais ou menos exitosas desse catálogo de remédios, o que lhe valeria o título de Defensor dos Índios. 
Além de impulsar a promulgação das Leis de Índias de 1512 e de 1542, onde se estabeleciam medidas protetoras para os indígenas, desde a proibição do trabalho escravo até a instauração de férias obrigatórias de 30 dias, Las Casas foi um ativo motor de fomento à emigração de trabalhadores que levassem a cultura de trabalho honrado e vida humilde às comunidades igualitárias, que enuncia e que, depois, serão emuladas pelos "Hospitales Pueblo", do Bispo Vasco de Quiroga, de inícios do século XVI, as missões jesuíticas do Paraguai e Alto Paraná e dos falanstérios impulsados por europeus durante o auge das utopias sociais americanas do século XIX, todas com intensos utópicos.

Infelizmente, em raríssimas ocasiões, tais empreendimentos tiveram sucesso. Em primeiro lugar, poucos trabalhadores queriam se aventurar em uma empresa desse grau de perigo para se conformarem apenas com uma pequena exploração comunal da terra ou do garimpo. As primeiras expedições estavam formadas por penados e aventureiros, que nada tinham a ver com as condições formuladas nos "Remédios" de Las Casas.

Em outras ocasiões, como na iniciativa de Las Casas de empreender a primeira fundação da colônia em Terra Firme (América Central), o assentamento da Vera Paz, formada por trabalhadores isentos de armas e sem soldados, estes foram sacrificados pelos indígenas canibais. Tal realidade foi um dos argumentos de Sepúlveda para rebater as propostas de Las Casas na Controvérsia de Valladolid, a de levar aos lavradores colonos a uma morte segura, se não houver o concurso da força armada para levar "o evangelho e os bons costumes aos povos incultos."

Segundo se definem estas duas concepções macro sobre o "encontro" de culturas, ficam já assentadas as bases de duas diferentes formas de entendimento da evangelização, as quais não apenas comportam uma forma organizativa coletiva determinada e antagônica, mas o que é fundamental ao novo sistema, um disciplinamento dos corpos absolutamente oposto em ambas concepções.

Para Sepúlveda, a única forma possível é através da imposição pela força dos novos costumes e religião, para que sucessivas gerações se integrem pacificamente aos postulados do Império-Papado, com incentivos reais ao lucro dos conquistadores, de forma que se justifiquem riscos e trabalhos. Assim, Sepúlveda postula no seu Demócrates Alter:

Así pues, solamente con el hierro se compensan los demás metales que los españoles toman de los bárbaros y se les devuelve con creces el beneficio; ¿y cuánto más se acrecienta éste, si a él se une el trigo y la cebada y demás clases de cereales y legumbres? Añádanse los caballos, las mulas, los asnos, los bueyes, las ovejas, los puercos, las vides e infinita clase de árboles (...). Con el beneficio de cada una de esas cosas en particular, se supera con mucho la 
utilidad que los indios obtenían del oro y la plata; cuánto más todavía si nos fijamos en las letras, de las que por completo estaban ellos faltos, del todo desconocedores de la lectura y escritura; o en la cultura o en las instituciones y leyes excelentes, o en un beneficio que sólo él vale por todas las utilidades de las demás cosas, a saber: el conocimiento de Dios y la religión cristiana, que vela por la salvación de muchos millares de almas que seguramente habrían de perecer lejos de ella(...). Si conocen y advierten esto quienes se empeñan em impedir esta expedición, para que los indios no pasen al dominio de los cristianos, tales hombres, yo sostengo que no favorecen humanamente a los indios, como ellos quieren parecer, sino que les privan cruelmente de muchos y grandes bienes. (SEPÚLVEDA, 1997, p. 98).

Para tal, a "encomenda" revela-se fundamental, na qual o encomendero colonizador disporia de um grupo indígena com a responsabilidade de ensinar a doutrina cristã e os princípios civilizatórios e, em troca, seria a ele entregue o trabalho dos encomendados nativos, possuindo total jurisdição sobre eles e as famílias. O fundamento final estaria em um tardofeudalismo medieval, paralelo à última conquista dos reinos muçulmanos da península, que não seria do total agrado dos monarcas modernos da Espanha, que queriam garantir a preeminência da sua soberania junto com a subsequente cobrança do quinto real dos produtos,e especialmente, do ouro e da prata. Esse tomismo inicial é enriquecido decisivamente através das traduções diretas de Aristóteles por parte de Pomponazzi e seu discípulo Sepúlveda do estagirita, enquanto preceptor de Alexandre o Grande, e que formula uma política e filosofia imperiais.

Os principais motivos do domínio sobre os povos indígenas elencados por Sepúlveda seguem princípios do estagirita na sua teoria da caça de selvagens que desconhecem a civilização e podem ser adquiridos como "res nullius". Poderiam se formular assim: são incivilizados por não possuírem leis escritas, são idólatras, cometem o pecado nefando e realizam sacrifícios humanos intoleráveis. Como se aprecia, são todos argumentos centrados finalmente nos indivíduos e suas práticas culturais, classificados segundo a inscrição deles na comunidade enquanto corpos: o corpo cultural (não escrito), o corpo da fé (deuses e sacrifícios) e o corpo de gozo (práticas homossexuais permitidas). Assim, Sepúlveda (1892), na sua obra mais conhecida, Democrates Alter, sive de iustus belli causis apud indos, apenas publicada durante o reinado de Carlos III, depois de enunciar as causas, enumera os princípios da dominação, também sobre os corpos, que toma diretamente de Aristóteles, e que são fundamento e substância da Lei Natural. Tal Lei Natural é construída por Sepúlveda como aquela que provém dos filósofos não cristãos, notadamente Aristóteles, conseguindo harmonizar esta com os preceitos cristãos posteriores. 
De esto resulta que en cierto modo brota de la naturaleza la obtención de riquezas por medio de la guerra, puesto que una parte de ella es la facultad de la caza, de la cual conviene usar no sólo contra las bestias, sino también contra aquellos hombres que habiendo nacido para obedecer rehúsan el dominio, pues tal guerra es justa por naturaleza. (SEPÚLVEDA, 1997, p. 56).

Portanto, "são escravos por natureza, como dizem que acontece em certas regiões e partes do mundo, ou porque, devido à sua depravação de costumes ou por outra causa, não podem ser mantidos de outro modo no cumprimento do dever" (SEPÚLVEDA, 1997, p. 130). Sepúlveda elenca os princípios do estagirita, que fundamentam o sistema no domínio total sobre esses corpos:

En todo esto se ve con claridad que es natural y beneficioso el dominio del alma sobre el cuerpo, de la razón sobre el apetito, al tiempo que la paridad o desigualdad de dominio es perniciosa para todos. Y, según enseñan, por esta misma medida y ley se rigen corrientemente los hombres y los restantes animales. Pues siendo entre los animales mejores los domesticados que los salvajes, no obstante, a los primeros les resulta mejor y más beneficiosa la sumisión al gobierno del hombre, ya que así y no de otro modo se conservan. Por la misma razón el marido tiene dominio sobre su esposa, el adulto sobre el niño, el padre sobre el hijo, en una palabra, los superiores y más perfectos sobre los inferiores y más imperfectos. Y enseñan que esta misma razón vale para los demás hombres en sus mutuas relaciones, pues entre ellos hay una clase en que unos pocos son por naturaleza señores y otros por naturaleza esclavos. (SEPÚLVEDA, 1997, p. 55).

Como diria um dos Censores do Conselho Real que impedira posteriormente a publicação em Espanha do Democrates Alter - apenas no iluminismo do século XVIII -, Sepúlveda exibe o mais descarnado aristotelismo, que é pouco cristão, pelo que a obra não foi impressa (LOSADA, 1973). O dominicano Las Casas, pelo contrário, embora fundamente também seus princípios no tomismo como neoescolástico e membro da Ordem de Predicadores, consegue conferir ao livre arbítrio e, portanto, ao corpo, uma visão diametralmente oposta. Já desde os primeiros escritos e nas primeiras linhas da Brevíssima, apresenta os indígenas, não apenas nas suas qualidades morais, mas dando ênfase à sua corporeidade, desqualificando-os para o trabalho à grande escala que requerem os minérios:

Todas estas universas e infinitas gentes, a toto genere, crio Dios los más simples, sin maldades ni dobleces, obedientísimas, fidelísimas a sus señores naturales y a los cristianos a quien sirven; más humildes, más pacientes, más pacíficas y quietas, sin rencillas ni bollicios, no rijosos, no querulosos, sin rancores, sin odios, sin desear venganzas, que hay en el mundo. Son así mesmo las gentes más delicadas, flacas y tiernas en complisión y que menos pueden sufrir trabajos, y que más fácilmente mueren de cualquiera enfermedad; que ni hijos de príncipes y señores entre nosotros, criados en regalos y delicada vida no son más delicados que ellos, aunque sean de los 
que entre ellos son de linaje de labradores. Son también gentes paupérrimas y que menos poseen ni quieren poseer de bienes temporales. (LAS CASAS, 2006, p. 13).

Os desejos de ouro e carne dos cobiçosos colonizadores se sentem de forma direta nos corpos: este será o leit motiv recorrente ao longo da Brevíssima Relação da Destruição de Índias, que, na sucessão de capítulos, relata os abusos dos espanhóis sobre a integridade corporal dos indígenas nos diversos espaços ocupados. A Brevíssima vem a ser um opúsculo de natureza divulgadora - panfletária para seus inúmeros detratores - por vários motivos. Primeiro, pela escolha do castelhano como língua de mais fácil acesso, enquanto seu antagonista, Sepúlveda, escreve quase exclusivamente em latim. Segundo, porque se utiliza de extraordinária brevidade, se comparada com a longa História das Índias, do próprio Bartolomeu, obra em três grossos volumes. E, finalmente, pela própria natureza discursiva desta memória pessoal ou de relatos de testemunhas, que apela à truculência - não isenta de valor histórico - e que se serve de imagens vivas, breves descrições e ações vertiginosas de fácil compreensão e ágil leitura pelos leigos, o que terminaria por fazer desta obra, traduzida a quase todas línguas europeias e com um extraordinário volume de edições até hoje, de um autêntico best-seller. Veja-se uma simples mostra desse catálogo:

Comúnmente mataban a los señores y nobles desta manera: que hacían unas parrillas de varas sobre horquetas y atábanlos en ellas y poníanles por debajo fuego manso, para que poco a poco, dando alaridos, en aquellos tormentos desesperados se les salían las ánimas. Una vez vide que teniendo en las parrillas quemándose cuatro o cinco principales señores (y aun pienso que había dos o tres pares de parrillas donde quemaban otros) y porque daban muy grandes gritos y daban pena al capitán o le impidían el sueño, mandó que los ahogasen, y el alguacil, que era peor que verdugo, que los quemaba (y sé cómo se llamaba y aun sus parientes conocí en Sevilla) no quiso ahogallos, antes les metió con sus manos palos en las bocas para que no sonasen, y atizóle. (LAS CASAS, 2006, p. 22).

Curiosa a convergência com a introdução de Vigiar e Punir sobre a disciplina dos corpos e sua evolução através dos tempos, como descreve Michael Foucault (1972), criando um efeito não desejado, provavelmente intuído pelo Conselho Real no ato de censura das publicações de Sepúlveda e na promulgação das leis de índias de 1515 e 1546, no sentido de levar o controle dos corpos para técnicas mais acuradas, e não aquelas que despertam a compaixão pelas vítimas e igualam os carrascos aos criminosos:

Damiens fue condenado, el 2 de marzo de 1757, a "pública retractación ante la puerta principal de la Iglesia de París", adonde debía ser "llevado y conducido en una carreta, desnudo, en camisa, con un hacha de cera encendida 
de dos libras de peso en la mano"; después, "en dicha carreta, a la plaza de Grève, y sobre un cadalso que allí habrá sido levantado [deberán serle] atenaceadas las tetillas, brazos, muslos y pantorrillas, y su mano derecha, asido en ésta el cuchillo con que cometió dicho parricidio, 1 quemada con fuego de azufre, y sobre las partes atenaceadas se le verterá plomo derretido, aceite hirviendo, pez resina ardiente, cera y azufre fundidos juntamente, y a continuación, su cuerpo estirado y desmembrado por cuatro caballos y sus miembros y tronco consumidos en el fuego, reducidos a cenizas y sus cenizas arrojadas al viento".2 "Finalmente, se le descuartizó, refiere la Gazette d'Amsterdam.3 Esta última operación fue muy larga, porque los caballos que se utilizaban no estaban acostumbrados a tirar; de suerte que en lugar de cuatro, hubo que poner seis, y no bastando aún esto, fue forzoso para desmembrar los muslos del desdichado, cortarle los nervios y romperle a hachazos las coyunturas. (FOUCAULT, 2002, p. 6).

O ideal lascasiano era o de integração pacífica e voluntária dos índios à Cristandade por meio de uma pregação, de modo que deviam ser aprendidas e conservadas as línguas nativas, e os nativos participarem nas novas escolas e universidades do Novo Mundo; ideal que os franciscanos levaram a bom termo durante a fase inicial prévia ao Concílio de Trento. Mediante essas práticas missionárias, garantir-se-ia uma autêntica adesão ao ideal e Igreja cristã, integrando também uma confederação com os Reinos da Espanha - teoria de outro dominicano, Francisco de Vitoria).

Frente a tais ideais, a teoria de dominação de Sepúlveda, embora autenticamente moderna na sua concepção e aplicação imperial à quarta parte do Mundo, possui profundas raízes em um mundo feudal do direito baseado na força, no qual a segurança e identidade jurídicas dependem apenas da sujeição corporal à vontade e desejos de um senhor, cujo senhorio se estende e se entende por herança ou pela guerra. Na realidade da colonização, era a via mais rápida, porque, embora existissem os impostos do Quinto Real, todas estas empresas eram com risco de vidas e recursos particulares dos "avançados", cujo prêmio menor seria a encomenda de índios e o almejado, a descoberta do Eldorado.

Para tal, Sepúlveda qualifica previamente os indígenas, não apenas como bárbaros, que, de alguma forma, compartilham a civilização, mas como seres carentes de cultura, o que lhes converte em seres equivalentes a animais selvagens e juridicamente res nullius, suscetíveis de serem caçados, como institui Aristóteles, pensador que, para Sepúlveda, é o Alfa e Ômega do Direito Natural, conforme a razão e em nada contrário ao Direito Divino. Neste ponto, se é profundamente medieval, enquanto não são súditos do rei absoluto, mas servos ou vassalos do conquistador.

Assim, Bartolomeu conseguirá que sejam aprovadas as leis protetoras de indígenas - leis de Burgos, 1512, e Leis Novas, 1542 -, que, na realidade, os protege enquanto súditos 
submetidos diretamente à Coroa Real, e como tais, sujeitos ao pago de impostos e à defesa das armas reais em caso de guerra, uma característica fundante da primeira modernidade. Tais argumentos encontram-se nos memoriais que Las Casas envia regularmente ao Conselho Real nos pleitos como Defensor dos Índios, instituído em tal cargo pelo regente Cardeal Cisneros em 1516.

Um dos argumentos do Democrates Alter para justificar o direito de ocupação dos territórios indígenas e da própria integridade corporal deles seria a comparativa com as virtudes dos reinos civilizados:

Compara ahora estas dotes de prudencia, ingenio, magnanimidad, templanza, humanidad y religión con las de estos hombrecillos en los que apenas se pueden encontrar restos de humanidad, que no sólo carecen de cultura, sino que ni siquiera usan o conocen las letras ni conservan monumentos de su historia, sino cierta oscura y vaga memoria de algunos hechos consignada en ciertas pinturas, carecen de leyes escritas y tienen instituciones y costumbres bárbaras. Y a propósito de sus virtudes, si quieres infórmate de su templanza y mansedumbre, ¿qué se va a esperar de hombres entregados a toda clase de pasiones y nefandas liviandades y no poco dados a alimentarse de carne humana? (SEPÚLVEDA, 1997, p. 65-66).

Seguindo Abril-Castelló (1984), o contra-argumento de Las Casas será elaborado no que se chama Duodécima Réplica, na qual se defende a integridade cultural dos reinos indígenas, baseada no reconhecimento de que eles já possuem uma religião organicamente constituída e, portanto, estão organizados em uma cultura com traços civilizatórios dignos de autonomia e autotutela, e que a evangelização destes povos haverá de ser fundada sempre no livre arbítrio, sem coação de nenhum tipo. Aventuramos desde estas linhas a impronta tomista que preside o raciocínio neoescolástico de Las Casas, partindo de que todos os homens são racionais e igualmente criados por Deus, e que, se Deus houvesse criado tanta quantidade de seres subhumanos e carentes de razão, seria algo absurdo, um erro contra natura e contra o próprio princípio divino, e é impossível um erro de Deus de proporções tão gigantescas. Poderia se destacar como central este trecho da Duodécima Réplica às “considerações temerárias do doutor Juan Ginés de Sepúlveda":

Item, antes que los infieles se bapticen no son súbditos de la Iglesia, como arriba está tocado y en nuestra Apología muy largamente probado. Y así, hablando simpliciter et absolute no les puede poner ni quitar señor ni ellos obedecelle, sino muy de per accidens, en algún caso muy particular, como si impidiese aquel tal señor sólo él la predicación de la fe. (LAS CASAS apud ABRIL-CASTELLÓ, 1984, p. 249). 
Podemos concluir que não existe no campo da arte, da literatura, das discursividades ou concepções éticas, um salto repentino desde as mal chamadas trevas medievais - conceito que simplifica dez séculos de história europeia e que oculta histórias das outras partes do Mundo para um resplandecente e idealizado Renascimento, de forma quase mágica e, sem dúvidas, simplificadora.

Ambas as concepções, embora plenamente modernas pela natureza desconhecida das novas realidades analisadas, necessariamente haverão de partir desde a experiência, imaginário, desejos e cultura de profundas raízes medievais, que informam o fazer e o pensamento sobre a Conquista.

Nesse contexto, pensamos ter demostrado a natureza medieval de parte substancial dos princípios éticos que suportam a ação e pensamento dos contendentes de Valladolid, o Humanista Sepúlveda, que se vale do Tomismo, dos Padres da Igreja e da Bíblia para fundar o pensamento imperial moderno, e Bartolomé de las Casas, desde um neoescolasticismo, a princípio ultrapassado para a época, servindo para defender e consolidar uma visão jusnaturalista mais humana e de respeito pelos povos do Novo Mundo.

\section{REFERÊNCIAS}

ABRIL-CASTELLÓ, Vidal. La Bipolarización Sepúlveda-Las Casas y sus Consecuencias: la Revolución de la Duodécima Réplica. In: Ramos, García, Pérez et al (Org.) La Ética en la Conquista de América. Madrid: CSIC, 1984.

ANABITARTE, Héctor. Bartolomé de las Casas. Madrid: Labor, 1992.

DUMONT, JEAN. El amanecer de los derechos del hombre - La controversia de Valladolid, Ediciones Encuentro: Madrid, 1997.

DUSSEL, Enrique. Ética de la Liberación en la época de la globalización y la exclusión. Madrid: Trotta, 1998.

FUENTES, Carlos. La Gran Novela Latinoamericana. Madrid: Alfaguara, 2011.

FOUCAULT, Michael. Vigilar y Castigar: Nacimiento de la Prisión. (Trad. Aurelio Garzón). Buenos Aires: Siglo XXI Ediciones, 2002.

HANKE, Lewis. La lucha por la justicia en la conquista de América. Madrid: Istmo, 1988.

LAS CASAS, Bartolomé de. Brevísima Relación de Destrucción de Indias. Medellín:

Editorial Universidad de Antioquia, 2006.

LOSADA, Ángel. Juan Ginés de Sepúlveda a través de su "Epistolario" y nuevos documentos. Madrid: CSIC, 1973. 
PEREÑA, Luciano. La ética en la conquista de América. Francisco de Vitoria y La escuela de Salamanca. Consejos Superior de Investigaciones Científicas: Madrid 1984.

PÉREZ DE TUDELA, Juan. Obras Escogidas de Fray Bartolomé de las Casas: Opúsculos, Cartas y Memoriales. Madrid: Atlas, 1958.

RODRIGUES, Juan Pablo. Bartolomeu de las Casas: a pena contra a espada. 2006. Dissertação (Mestrado). Programa de Pós-Graduação em Letras, Universidade Federal de Pernambuco, Recife, 2006. Disponível em:

https://repositorio.ufpe.br/handle/123456789/7816.

RODRIGUES, Juan Pablo. Juan Ginés de Sepúlveda: Gênese do pensamento imperial. 2010. Tese (Doutorado). Programa de Pós-Graduação em Letras, Universidade Federal de Pernambuco, Recife, 2010, in: https://repositorio.ufpe.br/handle/123456789/7053.

SEPÚlVEDA, Juan Ginés de. Democrates Segundo. Pozoblanco: Ayuntamiento de Pozoblanco, 1997.

SEPÚlVEDA, Juan Ginés de. Exhortatio Ad Carolum V. In: LOSADA, Ángel. Tratados Políticos de Juan Ginés de Sepúlveda. Madrid: IEP, 1963.

SOMEDA, H. Reflexión histórica sobre Bartolomé de Las Casas y la leyenda negra. Temuco: Universidad Católica de Temuco, 2012.

Recebido em: 23/05/2020 Aceito para publicação em: 26/11/2020 